\title{
2004-01-2365 \\ Architecture and Functionality of the Advanced Life Support On-Line Project Information System
}

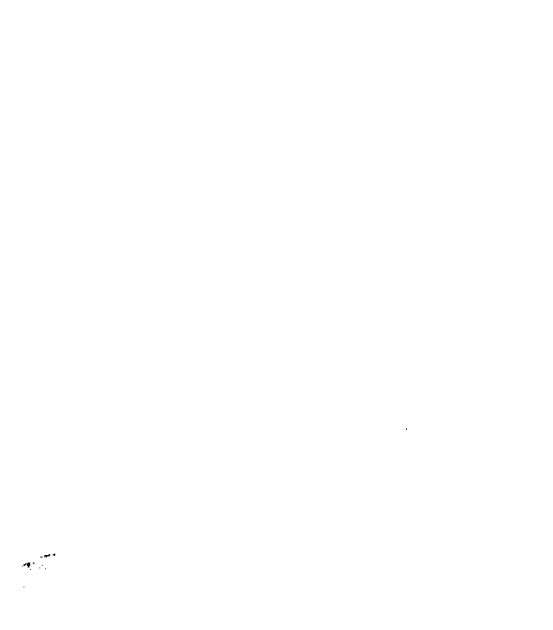

John A. Hogan

Rutgers, The State University of New Jersey/NASA ARC

Julie A. Levri

NASA ARC

Rich Morrow

Lockheed Martin Space Operations/NASA ARC

Jim Cavazzoni

Rutgers, The State University of New Jersey

Luis F. Rodriguez

National Research Council/NASA JSC

\section{Rebecca Riaño and Dawn R. Whitaker \\ Purdue University/ALS NSCORT}

\begin{abstract}
An ongoing effort is underway at NASA Ames Research Center (ARC) to develop an On-line Project Information System (OPIS) for the Advanced Life Support (ALS) Program. The objective of this three-year project is to develop, test, revise and deploy OPIS to enhance the quality of decision-making metrics and attainment of Program goals through improved knowledge sharing. OPIS will centrally locate detailed project information solicited from investigators on an annual basis and make it readily accessible by the ALS Community via a Webaccessible interface. The data will be stored in an objectoriented relational database (created in MySQL(B) located on a secure server at NASA ARC.
\end{abstract}

OPIS will simultaneously serve several functions, including being an research and technology development (R\&TD) status information hub that can potentially serve as the primary annual reporting mechanism for ALS-funded projects. Using OPIS, ALS managers and element leads will be able to carry out informed R\&TD investment decisions, and allow analysts to perform accurate systems evaluations. Additionally, the range and specificity of information solicited will serve to educate technology developers of programmatic needs.
OPIS will collect comprehensive information from all ALS projects as well as highly detailed information specific to technology development in each ALS area (Waste, Water, Air, Biomass, Food, Thermal, Controls and Systems Analysis). Because the scope of needed information can vary dramatically between areas, element-specific technology information is being compiled with the aid of multiple specialized working groups.

This paper presents the current development status in terms of the architecture and functionality of OPIS. Possible implementation approaches for OPIS are also discussed.

\section{INTRODUCTION}

\section{BACKGROUND}

Successful spacecraft/habitat design and development requires vast amounts of programmatic and technical information. These information needs are also userspecific, and range from the general level to detailed technology data. For example, project managers, systems analysts, hardware developers and other researchers will require a variety of data sets. 
II routine practice, most of this information is not centralized, if it is available at all. This necessitates scanning several non-uniform information sites, and possibly contacting researchers directly. With time, much information may become effectively lost, either through physical unavailability or incompleteness.

A contributing factor to data deficiency involves researchers that are new or external to the NASA environment, and who may be unaccustomed to the types of information required by ALS/NASA. For example, final reports from university research might contain only minimal focus on project integration, reliability, and the Equivalent System Mass (ESM) parameters of projected mass, power, volume, thermal and crew-time requirements. Individual reporting can also suffer from a lack of peer-review, veracity and accountability, and may also involve duplication of efforts due to a lack of awareness of prior research. This knowledge deficit can also extend to proposal review panels, and new managers with limited programmatic history.

To address these and other obstacles, new systems are needed to provide proper collection, archiving and dissemination of information. A primary feature would include the ability to provide a formalized and thorough data collection procedure that would gather comparable information sets from all researchers. Such systems would be developed to encompass the data needs of the information users (e.g., analysts, management, researchers). Data should be collected directly from the researcher, instead of being externally compiled by other parties, so that the greatest level of detail would be extracted. In addition to mandated data, such systems should also allow voluntary inclusion of supporting information that would be provided at the discretion of the researcher. Finally, data should be collected and disseminated in a user-friendly electronic format, and viewable by a broad base of authorized individuals.

\section{CURRENT ALS INFORMATION SYSTEMS}

Currently within the ALS program, the primary methods of transferring information from researchers to ALS managers include interim and final reporting, and publication and/or presentation of results in both NASA and external forums (e.g., Technical Interchange Meetings, conferences, workshops). In addition, the Office of Biological and Physical Research (OBPR) has established the annual on-line Taskbook system (http://peer1.nasaprs.com/peer_review/index.cfm). This system solicits a limited amount of general project information, including short task description and progress sections, investigator contact information, Earth benefits and bibliography. This system is effectively designed to provide a brief synopsis of Advanced Human Support Technology (AHST) projects to the general public.
Recently, significant effort has been undertaken to provide relevant ALS documents to the general public via the official ALS Program website (http://advlifesupport.jsc.nasa.gov/index.html). This site provides numerous documents, including the Baseline Values and Assumptions Document (Hanford, 2002), Reference Missions Document (Stafford et al., 2001), and the ALS Technologies List (Duffield, 2001). This allows users to quickly survey the ALS Project and gain a more detailed understanding of ALS goals, requirements and research issues.

Despite these advances, additional efforts are necessary to provide a consistent process to transfer detailed technology characteristics and development progress among ALS researchers, technology developers and the ALS Community (managers, analysts, researchers). The lack of thorough, accurate and comparable information presents a substantial hurdle to successful evaluation of technology development progress, trade/system studies, technology selection and metric calculations. A well-ordered, efficient means of collecting and transferring technology characteristics and status directly from the researcher/technology developer is therefore a pressing need in the ALS project.

\section{OBJECTIVES}

To address these issues, a comprehensive On-line Project Information System (OPIS) is being developed at NASA Ames Research Center (ARC) for the Advanced Life Support (ALS) Program (Levri et al., 2004; Levri et al., 2003). The objective of this three-year project is to develop, test, revise and deploy OPIS to enhance the quality of decision-making metrics and attainment of Program goals through improved knowledge sharing. This paper describes the OPIS background and development approach, and introduces the current key procedures and features of the system. Major areas of discussion include General Project Information (GPI) and Technology Information Forms (TIFs), user roles, security and general database features.

\section{OVERVIEW OF OPIS}

OPIS will centrally locate both general and detailed technology project information solicited from all ALS principal investigators (PIs) on an annual basis. This information will be made readily accessible to the ALS Community via a Web-based interface. The data will be stored in an object-oriented relational database (created in MySQL $($ ) located on a secure server at NASA ARC. See Figure 1 for a schematic of the overall OPIS concept.

OPIS will simultaneously serve several functions. OPIS will become the primary R\&TD status information hub, and can potentially serve as the primary annual reporting mechanism for ALS-funded projects. Using OPIS, ALS managers and element leads will be able to carry out 


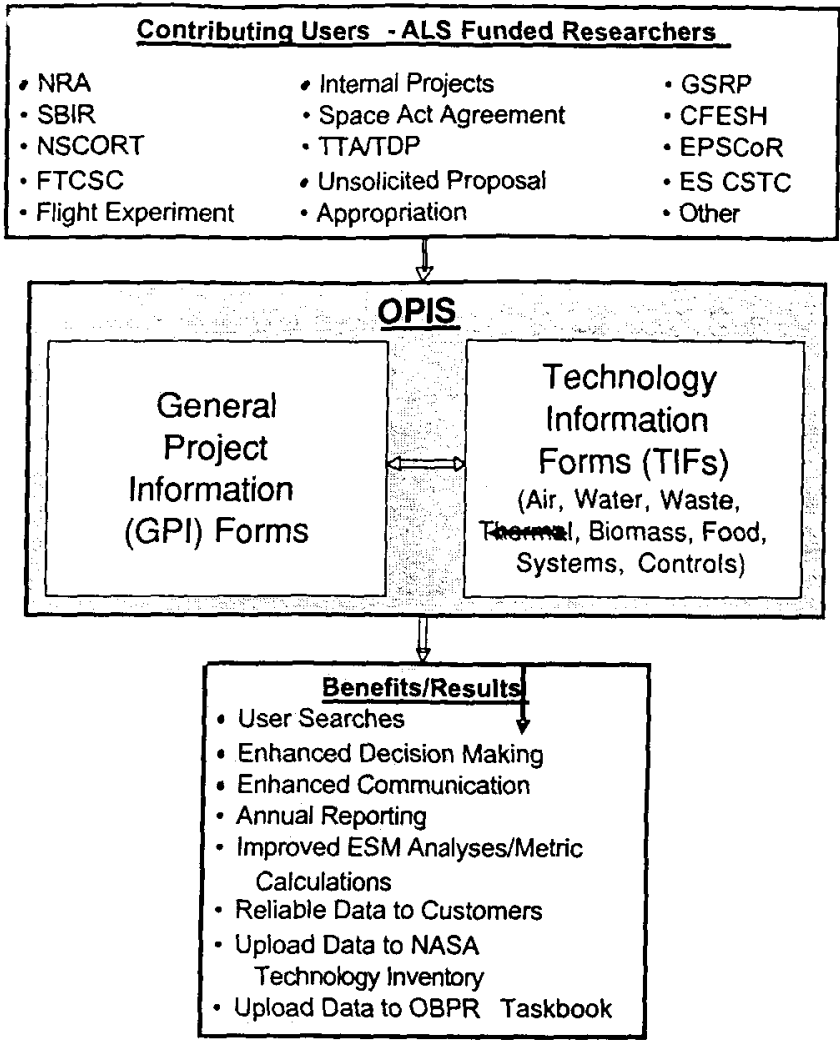

informed research and technology development investment decisions, and allow analysts to perform accurate systems evaluations. Additionally, the range and specificity of information solicited will serve to educate researchers and technology developers of programmatic needs. Likewise, researchers will be better

\section{Figure 1. OPIS concept diagram}

enabled to discern where program gaps exist, allowing more directed proposal submissions. This ability is critical to fostering technology capability for future missions, especially where future mission requirements are only approximate. Also, issues brought to light by OPIS may result in the evaluation and subsequent refinement of future mission requirements, as well as the Technology Readiness Level (TRL) metric.

It is anticipated that numerous benefits to the ALS Program will result from implementation of OPIS:

- Analysts will have access to the most current, accurate, thorough and relevant technology information. This will result in more accurate and meaningful results in analyses (including ESM studies) and Metric calculations. This will provide more detailed, accurate data to the OBPR Task Book and the ALS Baseline Values and Assumptions Document (BVAD) (Hanford, 2002), which summarizes top-level assumptions for system studies.

- The ALS Community will have ready access to researcher contact information and thorough project/technology descriptions. This will improve collaboration between researchers and pool resources to more efficiently address ALS needs. For example, data sets from a particular project can be posted to OPIS, making them readily available for model development and verification purposes by others. Feedback between researchers will also be enhanced. Such communication will result in better integration between subsystems.

- By co-locating detailed, thorough project information, research and technology development gaps in the ALS Program will be more easily identified, thereby facilitating recognition of issues for research proposal solicitations. Also, researchers will gain increased ability to generate desirable and innovative research ideas.

- Managers will have the ability to conveniently monitor project progress and establish research priorities in the ALS Program. Equipped with the ability to view project activity in a timely, convenient manner, ALS management will be better informed about the current state of the ALS Program, thereby enhancing decision-making.

- Annual reporting will be streamlined. Reporting will be centrally located and easily accessed by all ALS Community members. Administrative workloads in distributing reports will be reduced. Because of increased ALS Community visibility, researchers will also be more likely to provide accurate information, and in a timely manner.

- OPIS will inform researchers on the multitude of space-related concerns with technology development. The broad scope of OPIS will provide knowledge that enables researchers to address those concerns, thereby expediting TRLadvancement of technologies.

- The TRL scale may be defined in more detail from an ALS technology development perspective, as researchers respond to OPIS TRL-based requests.

- Development of a thoroughly tested project information system for ALS has the potential to serve as a template system for similar programs, both within and outside of NASA.

\section{OPIS DEVELOPMENT APPROACH}

The development of a comprehensive and interactive database such as OPIS requires numerous functions to be simultaneously addressed. Of principal interest is defining the source, type and level of detail of information needed to be collected. Once this has been established, implementation of OPIS then requires controlling user access to OPIS, defining and controlling user roles and privileges, reviewing user input prior to 
public viewing, and securing dissemination of sensitive information.

The OPIS development approach was designed to accomplish these tasks using the scheme depicted in Figure 2. Although tasks are listed sequentially, much of the work is iterative and parallel. The following sections describe the major tasks in detail.

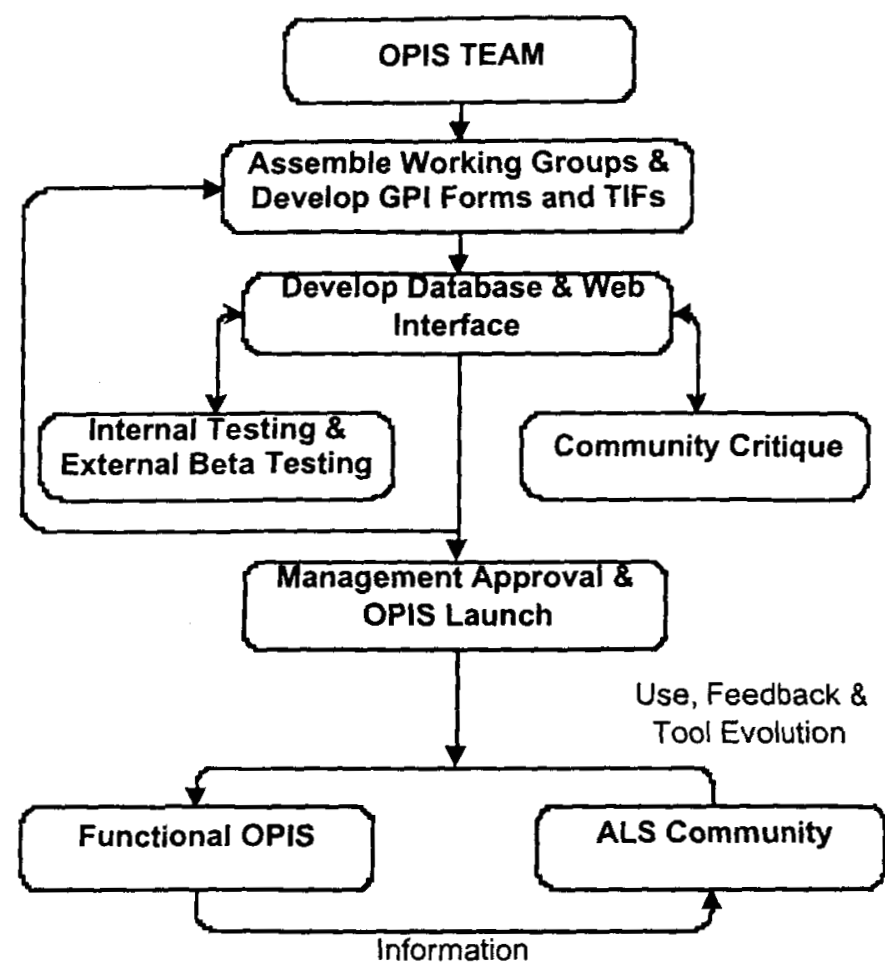

Figure 2. OPIS Development

DEVELOPMENT OF GENERAL PROJECT INFORMATION (GPI) FORMS

As may be seen from Figures 1 and 2, OPIS will capture and centralize two major types of information. The first is general, public domain information about all projects in the ALS Program. All ALS P/s will annually input/update information in the General Project Information (GPI) forms. GPI will encompass the information solicited in the OBPR Taskbook and the NASA Technology Inventory (NTI). This format could also allow attachment of project final reports. The specific information to be captured in the GPI forms is listed in Table 1.

\section{DEVELOPMENT OF TECHNOLOGY INFORMATION FORMS (TIFS)}

In addition to GPI, OPIS will solicit highly detailed technology data using TIFs (Levri and Hogan, 2002; Levri et al., 2002a \& b, Levri et al., 2001). TIFs will be developed for each of the major ALS areas that relate to technology development (Air, Water, Food, Waste, Biomass, Thermal, Controls, and Systems Analysis.)
TIF content will be carefully customized to each area, with the aid of specialized working groups, to facilitate form completion and searching. Additionally, each question posed in the TIFs will be customized for a particular Technology Readiness Level (TRL), as deemed appropriate by the TIF development group.

Efforts in the development of a specific TIF will aid in the development of future TIFs. For example, much of the information solicited in the existing Waste TIF (Levri and Hogan, 2002) will be applicable to other element TIFs. As a result, it is expected that each TIF will have a briet, areaspecific section combined with a lengthier, more "universal" section. Information from successive efforts can also provide valuable feedback to improve previous TIFs.

It is anticipated that some TIFs will require considerably more development effort than others, due to the broad scope of technologies in that area. For example, the Biomass Production (BP) TIF will be particularly challenging, as it covers a wide range of technology types, including crop cultivars, lighting and nutrient delivery systems, solid growth media, crop chamber environmental control, robotics and automation.

\section{WORKING GROUPS}

While creating the Waste TIF, it was realized that group critique is essential for a cogent and quality product. A Waste Working Group, consisting of the ALS Waste Element Lead, waste technology developers, researchers and system analysts, was utilized in creating the Waste TIF. Teleconferences were held at regular intervals to evaluate and improve TIF content and scope.

Because this method of group involvement proved to be highly successful, a similar format has been adopted for TIF development within each ALS area. Each working group will discuss form contents, scope and organization to guarantee that forms request the most suitable information from technology developers for that specific ALS Element.

\section{WEB INTERFACE AND DATABASE DEVELOPMENT}

The ALS Community will interact with OPIS via dynamic, Web-based Hyper Text Mark-up Language (HTML) forms. The OPIS Web site will be developed to allow PIs to $\log$ in to the OPIS system, dictate specific Read and Write privileges to particular individual team members, enter/modify data, submit forms, search the database and/or downioad completed forms. Because technology data is typically scenario-specific, large text space will be allotted to allow for data explanation. Users will also be able to upload/download supplementary documentation, such as graphics.

Information will be organized and centrally located in a database to allow straightforward retrieval. The database 
will be developed in MySQL $Q$, a widely utilized relational database management system. MySQL is marketed as open-source software via the General Public License for no charge by MySQL $A B \otimes$, a Swedish Company. MySQL is fast, easy to use, secure, and handles databases of more than adequate size for OPIS' projected needs. It has a flexible system of authorization that allows some or all database privileges (e.g. to create data, delete data or view data) to specific users. MySQL allows for use of encrypted passwords. Technical support is also widely available. 
Table 1 - General Project Information - Information Categories

\begin{tabular}{|c|c|}
\hline Information Category & Explanation of Information Requested \\
\hline Project title & Complete, official awarded title \\
\hline Abstract and keywords & Abstract and keywords for current fiscal year work \\
\hline Principal investigator & $\begin{array}{l}\text { Name, phone, email, fax, address, congressional district, title, institution, } \\
\text { institution type, Web page URL, curriculum vitae }\end{array}$ \\
\hline Associates & Contact information for project associates/co-investigators \\
\hline Project logistics & Contract number, technical monitor, responsible Center \\
\hline Solicitation type & NSCORT, NRA, TDP, TTA, SBIR, Appropriation, etc. \\
\hline Project type & Ground or flight \\
\hline ALS Element & e.g., Thermal, Waste, Water, Air, etc. \\
\hline Disciplines & e.g., Biological sciences, etc. \\
\hline History/Background Details & Past research efforts and results \\
\hline Funding & Current award starting and ending dates; fiscal year and total budget \\
\hline Objectives & Current fiscal year objectives \\
\hline Milestones & Current fiscal year milestones \\
\hline Progress & Progress report, including data descriptions and points-of-contact \\
\hline Methods & Data collection procedures and experimental design \\
\hline Mission applicability & Applicability to missions in the ALS Reference Missions Document. \\
\hline Earth benefits & Possible Earth benefits, including technology commercialization \\
\hline $\begin{array}{l}\text { Bibliography information } \\
\text { resulting from research }\end{array}$ & \multirow{2}{*}{$\begin{array}{l}\text { Abstracts for journals and proceedings, articles in peer-reviewed journals, } \\
\text { articles in other journals, award, bibliography, book, dissertations and } \\
\text { theses, journals, patent, presentation, proceeding entries, NASA } \\
\text { technical brief, etc. }\end{array}$} \\
\hline $\begin{array}{l}\text { Bibliography for sources used to } \\
\text { complete OPIS forms }\end{array}$ & \\
\hline Student activity & $\begin{array}{l}\text { Number of post-doctoral associates, Ph.D. students, other graduate } \\
\text { students, and undergraduate students }\end{array}$ \\
\hline Future plans & $\begin{array}{l}\text { Research plans (objectives, milestones) for future fiscal years within the } \\
\text { current award timeframe }\end{array}$ \\
\hline Research needed & Research needed in addition to that planned for the award timeframe \\
\hline Other & $\begin{array}{l}\text { Textual description of any aspects of the research that are not explicitly } \\
\text { solicited in the General Project Form. Users will also be able to upload } \\
\text { supplemental graphics, documents, etc. }\end{array}$ \\
\hline Technology development & $\begin{array}{l}\text { If a technology is being developed, the PI will be asked to complete a TIF } \\
\text { within the appropriate ALS area. }\end{array}$ \\
\hline
\end{tabular}

The PHP (PHP Hypertext Preprocessor) embedded scripting language will be used to pass messages between the Web-based HTML forms and the MySQL database. PHP is a free-of-charge, special-purpose language designed specifically for use on the Web and is particularly strong in its ability to interact with databases. Embedding PHP in HTML code makes PHP a "fast" language. PHP also has built-in features for communicating with MySQL; thus, MySQL and PHP are very commonly implemented together for dynamic Webbased database applications. Technical support is also widely available for PHP.

\section{COMMUNITY CRITIQUE AND TESTING}

To facilitate a user-friendly product with the broadest scope possible, OPIS development is utilizing a high degree of community involvement (outside of working groups). The OPIS concept and project progress has been presented multiple times at Systems Integration
Modeling and Analysis (SIMA) teleconferences, ALS Technical Interchange Meetings (TIMS), and at ALSbased conferences (Levri et al., 2003; Levri et al., 2004). Valuable feedback from these venues has been incorporated. Additionally, two members of the OPIS team are enlisted to continuously evaluate the "usability" and thoroughness of the forms being generated. Finally, at least two official, external beta-testers for each TIF will be enlisted once working models have been produced. This will serve to provide a "reality check" prior to the OPIS implementation, and also initiate populating of the database.

\section{OPIS IMPLEMENTATION}

After OPIS development and testing has been completed, and appropriate authorization from NASA managers granted, OPIS will be made available to the ALS Community. As OPIS will contain multiple individual components, implementation will be incremental. The 
GPI forms will be launched first, followed by the Waste TIF segment. OPIS will solicit extensive user feedback during form completion (discussed later), and will be utilized to enhance OPIS functionality with time. To facilitate compatibility with future (unknown) alterations, the structure of OPIS will be designed to readily allow modifications.

It is anticipated that all ALS PIs will be mandated to annually input/update GPI forms. In addition, technology development projects would require completion/update of a TIF. Information entered into OPIS will be available for search and download (contingent upon data confidentiality).

\section{OPIS PROCEDURES AND FEATURES}

\section{GENERAL}

Development efforts to date have addressed numerous required OPIS functions. Major areas include: delineation of the various OPIS user roles; access privileges and registration; form completion; project/technology home pages; security control issues; browse/search capabilities; and user help functions. The current status of these areas is presented in the following sections.

\section{USER REGISTRATION PROCESS}

Based on the roles that a user could possess, variable registration processes will be initiated. Pertinent registration processes are discussed below.

To determine who is mandated/allowed to enter GPI and TIFs, ALS Management will send the OPIS System Administrator a listing of all projects funded in the current fiscal year. Similarly, a PI may provide a list of suggested users for their project to the OPIS System Administrator. Other users may apply for registration by on-line request.

1) The OPIS System Administrator enters the information into the database, but does not "register" the PI.

2) An email will be automatically generated prompting the user to register (or verify, in the case of subsequent years) their information. This is performed so that the users are responsible for verifying their information (particularly country of citizenship).

Yearly verification of funding, citizenship, and the right to use OPIS will be required of every user. This verification process will remove inactive users who no longer have a need to use OPIS.

3) Using a link in the email mentioned in step 2, the user will access a user registration page. This page will request the following information (at a minimum):

- User's name, affiliation and contact information
- Reason for requesting a username and password

- Country of citizenship (and Green Card status if nonUS citizen)

- At least one ALS Reference (must be a Civil Servant working in the ALS Program)

4) After the registration application has been completed, the responsible NASA Official for OPIS will go through the application to determine whether or not the applicant should be granted a username and password. The applicant must have a valid reason for requesting access.

If the applicant is not a US citizen or US Green Card holder, or if the applicant is representing a foreign entity, the applicant must apply for a license to access OPIS. If a license is required, the ARC Export Control Officer will process that request.

5) Once registration has been approved by the responsible NASA Official, the approval is recorded in the database, and an email is automatically generated to that user indicating such. The email also provides a username and temporary password.

6) Upon first login, the user must read, acknowledge, and pass a "quiz" on the subjects of export control, invention disclosure and private information.

\section{OPIS USER ROLES AND PRIVILEGES}

MySQL has a flexible system of authorization that allows some or all database privileges to specific users. User registration and access privileges in OPIS will be assigned to allow for parallel completion of a single form. The flexibility of database privileges is advantageous because it accommodates users (such as industryrelated users) that resist providing detailed information on proprietary processes, as explained below.

Within OPIS, a PI will have the ability to assign "write" access to other individuals working on the project. Users with write access to a particular form may revise data contained in that form in multiple sessions, as the information will be stored in a temporary location that will be unavailable to the general ALS Community. When appropriate, certain information can be designated as "private", meaning that it can only be viewed by authorized users. Once a project TIF is fully completed, only the $P /$ will have the ability to officially submit the TIF to OPIS. A completed TIF must be approved by the Technical Task Monitor (TTM) before the data is made available to the ALS Community. Once opened to the ALS Community, a TIF cannot be changed unless deemed appropriate by an ALS Manager. For example, for necessary data correction, a form may be reopened and then resubmitted. However, multiple "resubmits" of a form will be discouraged to avoid the need for a cumbersome revision tracking system. 
Any person that either wishes or is required to access OPIS will be assigned one of nine roles as described below. Role type will not only regulate which information will be viewable, but will also guide the user to complete assigned tasks. Some roles (such as $P$ ) are projectspecific, while others (e.g., ALS Manager) are site-wide. "Project-specific" roles indicates that a given user may have a "default" role for one project and a "PI" role for a different project. Some roles are inclusive of others while some roles are unique in function. All roles require a login.

Note that Associate roles must be declared by the project Pl. All roles will be carried over from previous years, and will be easily "revived" by the PIfor the current year's project.

1. Default User: A Default User can search any information in OPIS that has not been designated as "private". Default users cannot enter information into the OPIS forms.

2. Associate I: This role may be assigned to research team members by the project PI. Such a member can write information into forms, but the user cannot read private information input from others working on that project. A pertinent example of this would be a project where one of the researchers is a private company which wishes to protect intellectual property from other members of the same project.

3. Associate II: This role may be assigned to research members by the project $\mathrm{Pl}$. Such a member cannot write to forms but can read private project information. This could allow research associates to become familiarized with a given project before they are allowed to contribute.

4. Associate III: This role may be assigned to research members by the project $P l$. Such a member can read private information and write to forms. The $P /$ would choose this option if the associate needs the ability to write data, and there are no reasons why the Associate should not be able to see other project-specific private data.

5. Principal Investigator (PI): This user assumes full responsibility of form content and assigning roles of other users on the project. This role includes full read and write privileges, as well as the ability to assign Associate roles to users.

6. Technical Task Monitor (TTM): This user is assigned by ALS Managers to approve forms before release to the ALS Community. This provides a check on data completeness and in some areas, accuracy. TTM's can read all information in their assigned forms but cannot write to forms (other than in the comments section).
7. ALS Manager: This role is intended for selected ALS managerial personnel. This role includes full read privileges, as well as the ability to assign TTM roles to forms. These individuals will utilize OPIS to review data for management concerns.

8. System Administrator: This role will carry out administrative functions such as creating projects and user accounts, and updating calendar content. This individual will not have access to private information.

9. Responsible NASA Official: This role will be assigned to a NASA Civil Servant. They will be able to assume the role of any other roles listed above. This insures that an OPIS task can still be performed should an assigned individual be unavailable for any reason.

Usernames will dictate the contents of the User Tasks Page, the first page seen upon login. This page will indicate for which projects a user has Associate, $P I$ and/or TTM roles. The User Tasks Page will provide a listing of user responsibilities, including links to relevant forms and home pages (discussed below). For forms in which the user is not an Associate, PI or TTM, the Browse/Search feature of OPIS can be utilized.

\section{FORM COMPLETION /PROCESSING}

All Pls of ALS Projects will be required to complete an OPIS GPI Form. The System Administrator will create individual GPI forms based on the details provided by ALS Managers. The PI (and designated Associates) will then be able to begin work on their project form as soon as they have a registered login account. A reminder email to complete OPIS forms is sent to $P / s$ at selected intervals prior to the due date.

While all Pls must complete GPI forms, only those researchers who are involved with developing a technology will be required to complete a TIF. An important issue regarding this is the identification of what research is actually technology related. For example, a researcher developing a water processor will be clear that it is a technology. In contrast, researchers working on plant cultivars may not perceive the cultivar as a technology (though within OPIS it is considered a technology).

To avoid ambiguity, OPIS will clearly define what are, or are not, considered technologies within each of the ALS areas. Researchers will be asked to read pertinent sections within OPIS at the onset of their research (initial login) to determine if they will need to complete a TIF. Researchers will be required to indicate whether or not they are developing a technology, and their conclusion will be reviewed by the assigned TTM. 
Once a technology has been created in OPIS, an empty form is automatically created for it. A link for the form will appear on the User Tasks Page for that PI. The PI may then assign Associates for that technology.

The completion status of both GPI forms and TIFs will be designated by the following five levels:

- Pre-Submission (The is the level during which the researchers are still compiling data and entering it into the forms)

- Submitted (At this level, the form has been completed and submitted to TTM for review).

- PI Attention Needed (At this level, the TTM has reviewed the form, but needs further information or clarification).

- TTM Attention Needed (At this level, the $P I$ has provided clarification, and is awaiting TTM re-check of the form).

- Approved (At this level, the TTM is satisfied with the level of detail, and makes the form available on OPIS)

These levels will be visually indicated on the User Tasks Page with color-coded icons (and a legend). This will allow for users with many tasks to quickly identify issues requiring their attention.

\section{PROJECT/TECHNOLOGY HOME PAGES}

Each $\mathrm{Pl}$ will be allowed (but not required) to create a Home Page for each project and/or technology. Home pages may include a team member contact list, pictures, reports, data, project-technology associations, and an event calendar. Information in Home Pages will be available to all OPIS users. OPIS users can also make comments and have discussions via Home Pages.

The Home Page feature will serve as a central repository for "extra data" which, to this point, has never been centralized. Additionally, archived project forms (from previous fiscal years) will be available on Home Pages. Home Pages are modifiable until the end of the funded work. After that point, the page will continue to be accessible, but no longer modifiable.

\section{SECURITY CONTROL MEASURES}

A critical aspect to the success of OPIS is proper control of various security concerns. OPIS must both adequately meet NASA and other Federal regulations and deliver a level of protection that provides researchers a high degree of comfort when providing information. The major areas of concern include: 1) Export control classification (and appropriate control of foreign national individual access); 2) Private material; and 3) Invention disclosure.
These issues are being addressed in the initial stages of the OPIS design, as discussed below.

Overall site security will be accomplished through multiple means. Two leveis of security are inherently present via the Linux and MySQL Login functions. In addition, users will be assigned encrypted passwords that must be changed on a yearly basis, but may be changed at any time.

Expert Control - As part of the account application procedure, all users will be mandated to indicate their country of citizenship, and whether they posses a US Green Card. If users are not a US citizen and do not possess a Green Card, their application will be processed by the ARC Export Control Officer. If the user is authorized, a license will be granted, which then allows some degree of access to the system. Users will be required to confirm their country of citizenship every year. US citizens that represent foreign entities will also be identified, and will need to apply for a license to view export-controlled material. For initial registration, users will require a reference from an authorized ALS Civil Servant, making it unlikely that unqualified users will be able to gain access to OPIS.

Invention Disclosure - If a user feels they have an invention, they are required to disclose that invention to their funding agency. Funding agencies include both the NASA entity, and the institution (e.g. University, Research Park) at which the researcher resides. Once information has been posted to OPIS, it has entered the public domain and is then subject to applicable patent application regulations.

Private Data - Individual sections of TIFs may be marked as "private". Only individuals who have PI, Associate /lor III, TTM/Manager or Responsible NASA Official roles for the project will have access to private information. This will allow confidential commercial information to be included without risk of disclosure to unauthorized individuals. In addition, comments (discussed below) made to any sections which are marked as private will inherently become private.

\section{SITE-WIDE HANDLING OF COMMENTS}

As OPIS is being designed to act as a dynamic and interactive tool for information transfer, user comments on submitted information will be allowed and encouraged. With this feature, any user who can view information can make comments about that information.

Three phases of form status will be used to filter comments made about information. These three phases are 1) Pre-submission, 2) Pre-approval, and 3) Approved. Only the Pland Associates will be able to see comments from the Pre-submission phase. This provides a private environment in which Pl's and 
Associates can discuss the contents of a form. Only Pl's, Associates and TTMs will be able to see comments from the Pre-approval phase. This allows for negotiation of form contents privately with the TTM. As mentioned previously, if the contents of a form are designated as private, then the comments about that information are also private. Thus, only users who have proper access may view/write comments during the Approved phase.

Comments may be made to any section of a GPI form or TIF, or about an uploaded document on a Home Page. The identity of the commenter and other tracking information (e.g., comment date/time) will be captured.

The ability to make comments about the content of OPIS forms could prove to be a very valuable and heavily-used feature of the site by enabling users to:

- Openly discuss and share information on data, in "discussion board" format

- Allow Pls and Researchers to upload and share valuable data as it is obtained, rather than waiting until the final (e.g., year-end) submission

\section{INFORMATION RETRIEVAL}

Users can obtain desired information through various means, including on-line browsing and searching of forms (these functions are discussed separately below). Pages will have a "download data" function which will allow the user to download any of the GPI forms or TIFs for their own archival or off-line purposes in a format (.PDF) that is visually identical to what users see onscreen. Characteristics of these functions are detailed below.

Browsing - Browsing both GPI and TIFs will first display a list of projects or technologies, categorized by element. Data on the browse pages will be sortable based on:

- Project or technology element

- Project or technology title

- Project or technology Pl's last name

- Project or technology status

- TTM Last Name

- TRL Level (Technologies only)

- Institution name

- Funding source (Projects only)

Searching - Searching will require an intermediate step of compiling a search form from among the vast array of possible search fields for both GPI and TIFs. Users will do this by first selecting only the relevant search sections of the GPI or TIFs, and "compiling" their search form (which will allow them to search on only the fields within those relevant sections).

\section{ONLINE/OFFLINE HELP \& AUTOMATION}

Although OPIS forms are being designed for intuitive use, extensive on-line and off-line help will be provided. Examples include, but are not limited to:

- Descriptive and succinct text will be visible at the top of each page informing the user the purpose of each field and what is expected of the user.

- Easily accessible, and constantly updated Frequently Asked Questions (FAQ).

- A clear description of roles \& responsibilities within OPIS (e.g., a PI must fill out their Project forms, a PI must initiate TIFs, etc). When users are assigned a new role on a particular project, they will be able to quickly understand what responsibilities this role entails.

- An extensive question-based help section (l'm trying to perform a certain task. How do I do this?). This help will also include several tutorials in the form of online movies (showing the actual working software, and tracing the tutor's mouse across the screen as the tutor describes an action).

- Making important documents regarding security issues such as export control, invention disclosure, and private information available and readily accessible.

- Automating items such as "I forgot my password", emailing notifications of important events inside of OPIS (e.g., your account has been approved, form status changes).

- Additionally, offline help will be available, and contact information for technical support resources will be prominently displayed.

Provisions will also be made to allow researchers to supply feedback regarding issues encountered while completing the form. Each page will possess a visible area that prompts the user to provide the feedback. This information will allow the OPIS team to identify and modify areas that are notably problematic.

\section{PROJECT RISK MANAGEMENT}

As with any novel endeavor, an element of risk is present in the OPIS project. The OPIS team will utilize the following approaches to minimize project schedule risk and ensure the development of a successful, high quality product: 
- OPIS Web pages will be developed in a hierarchical manner. Data collection pages for the GPI forms are being developed first. Next, the first-priority TIF information will be developed in each element area. Finally, collection pages for secondary-priority TIF information in each area will be developed. With hierarchical development, the benefits of OPIS are not "all or nothing". If OPIS is de-scoped, the most critical goals will still be achieved by collecting critical data first (e.g., there is an urgent need for accurate data for effective Metric calculations).

- The OPIS Team has considered historical and currently funded ALS projects to ensure that the scope of OPIS TIFs is adequate to capture the scientific/engineering information generated by each project.

- The OPIS Team will implement software tools to reduce the workload in Web page development as much as possible. For example, the team is using Zend Studio $\otimes$ to speed the development of the database.

- Overlap between TIFs will be identified. Although detailed customization of all TIFs is ideal, "universal" areas can be emphasized to decrease specialization efforts and TIF development time.

- Community involvement in OPIS development increases the probability of success. By utilizing working groups to develop TIFs, the ALS community is involved from the inception. In essence, both the individuals who request and submit OPIS forms will help guide their development. Form scope, content and organization will also be critiqued in broader venues, such as ALS TIMs.

- Internal testing and external beta-testing increases the chance of success. Each Web page will be internally tested with example data for appropriate content, ease of data entry, ease of searching and visual appeal. Each TIF will also be beta-tested externally by two technology developers. External beta-testing is expected to provide invaluable feedback.

\section{STATUS OF GPI \& TIF DEVELOPMENT}

A first version of the GPI forms has been completed and coded into dynamic HTML pages. These forms encompass all information that is currently being solicited in the OBPR Taskbook and the NASA Technology Inventory, plus additional information. These forms are being coded into a format that can be incorporated into OPIS. Communication has commenced with Taskbook and NTI personnel, and it is anticipated that OPIS will eventually automatically feed this general (non-private) information to them, thereby decreasing researcher and TaskbookNTI workload.
TIF forms development has been initiated for the Waste, Water, and Biomass Production (BP) areas (see Levri et al., 2003 for detailed information regarding Waste TIF). The Waste TIF has been converted from a textual format to an HTML format and is being incorporated into OPIS. A preliminary draft of the Water TIF has been completed and will undergo translation into HTML code after further review from the Water Working Group. The BP TIF has undergone initial identification of critical topics regarding form structure and solicitation scope, and the corresponding working group formed.

First-year Milestones - OPIS is in the first of a projected three-year project duration. Milestones anticipated to be completed by the end of the first year are summarized below.

- General Project Information forms will be developed and implemented.

- Browse and Search capabilities will be functional and incorporated into the GPI forms.

- Home Page capability will be developed and launched. This feature will be functional in combination with the GPI forms.

- The Waste TIF will be developed, beta-tested and launched. It is anticipated that waste researchers will be the first users of OPIS TIFs.

- The Water TIF will be developed and beta-tested. POTENTIAL FUTURE OPIS FEATURES

Project Expansion - The OPIS concept is one that would benefit many project management environments. Upon successful launch and multi-year implementation in the ALS Program, OPIS could be extended to encompass the full AHST Program. Upon successful use in the AHST Program, the OPIS system has the potential to be expanded to a number of different programs within NASA. A substantial level of "universality" already exists within the General Project and Technology information Forms, allowing rapid implementation in other Programs.

TRL Determinant - By making the OPIS requests TRLbased, it is anticipated that over several years, OPIS will gain knowledge of which technology information is generally known by researchers at a particular TRL. The ALS Program may therefore ultimately generate a list of issues that can be used to more accurately and objectively determine TRL. Such information, along with post-coilection data analysis, may aid in fine-tuning TRL definition beyond the existing, somewhat subjective scale. Such fine-tuning has the potential of aiding all of NASA, and other entities that have adopted the TRL concept (Graettinger et al., 2002).

Feeding the NASA Technology Inventory and OBPR Taskbook - The OPIS contents in the GPI have been designed to encompass the information requested by 
the NASA Technology Inventory (NTI) and the OBPR Task Book. OPIS will also solicit detailed technology data that is not encompassed by these systems. Consequently, if deemed appropriate by ALS and NTI/OBPR management, the ability to feed information directly from OPIS into the NTI and Task Book can be automated, via methods such as Extensible Mark-up Language (XML) using Hyper Text Transfer Protocol (HTTP), eliminating duplicate data entry by PIs.

Supplying Data to the Technology Integration Agent (TIA) Effort - Although in the preliminary development phase, the TIA effort in Bioastronautics and Fundamental Space Biology at NASA Ames Research Center is another potential OPIS customer. The goal of TIA is to match NASA's requirements to appropriate technologies. OPIS can serve as a primary resource for TIA researchers to investigate ALS technology capabilities and how those technologies might be applied within NASA and elsewhere. OPIS progress will be reported to TIA researchers on a regular basis to assure that TIA needs are encompassed in the TIFs.

Data Transfer to the BVAD. ALS Equipment Database and ALS Metric Calculator - The degree of detail solicited by OPIS far exceeds that of other AHST/ALS database efforts. For example, the BVAD (Hanford, 2002) and the OBPR Task Book are not designed to capture the information necessary to sufficiently evaluate technical aspects of technology development and fundamental research, as OPIS will. Also, detailed hardware data is needed for the ALS Equipment Database, which ultimately supplies information to the ALS Systems Analysis Tool (ALSSAT) to aid in calculating the ALS Metric values. Such detailed information is necessary for analysts to make accurate evaluations of technology options and to aid managers in pinpointing areas in need of further R\&TD. To fulfill this need, OPIS is expected to serve as a data source to the ALS BVAD and Equipment Database for computation of the ALS Metric. By having annual updates of OPIS technology information, changes in the ALS Metric value can be tracked in relation to technology improvements.

Input of Historical Data - Once OPIS has been established, it would be valuable to provide a mechanism for historical project/technology information to be added. This would greatly improve the overall value of OPIS as a means to centrally locate pertinent historical and current technical data. Although it would be unrealistic to attempt to include all past ALS projects, key technology development efforts may be selected. This is particularly relevant to technologies that have undergone extended development, but are currently not funded.

Progress/Final Reporting Mechanism - In an effort to create a singular electronic presence, it is logical to site final reporting in OPIS. This would effectively compile all information about a project in one location. As with all other data, provisions would be made to make the final reports searchable, and subject to appropriate security and export control constraints.

Automatic Generation of ALS Highlights - OPIS PI'S could be prompted on a regular basis to submit a report of recent progress. The submittals of all Pl's could be compiled in a single report, ready for editing and distribution by ALS Managers.

Repository/Link Site for Researcher Resources - In addition to serving as a database of individual projects, OPIS could readily be expanded to contain other sources of information. For example, all references regarding author's publications, literature used to complete the form, and generally useful references will be solicited from the researcher. The entries will be in searchable fields, rather than a non-searchable "cut and paste" method. This, in combination with parallel input of compiled historical references, would serve to provide an automatic updating of a single, searchable ALS reference source. Likewise, OPIS could also contain, or provide links to, other pertinent ALS and NASA documents, websites, on-line discussion boards, ALS roadmaps, NASA personnel databases, etc. Providing one well-organized site for the majority of ALS information would not only be highly convenient, it would also aid in unifying the ALS program in practice and in presentation to the public.

\section{ACKNOWLEDGMENTS}

The work reported in this document was supported by NASA through ALS Technology Development funding. The authors would like to thank reviewers for contributing valuable comments.

\section{REFERENCES}

1. Duffield, B.E. 2001. Advanced Life Support Technologies List. Doc. no. CTSD-ADV-397 National Aeronautics and Space Administration. JSC 39565

2. Greattinger, C.P, Garcia, S., Siviy, J.G., Schenk, R.J., Van Sickle, P.J. (2002) Using the Technology Readiness Levels Scale to Support Technology Management in the DOD's ATD/STO Environments. Carnegie Mellon Software Engineering Institute, Pittsburgh, PA. CMU/SEl-2002-SR-027

3. Hanford, A.J., (2002) "Advanced Life Support Baseline Values and Assumption Document" JSC47804, NASA Lyndon B. Johnson Space Center, Houston, Texas.

4. Levri, J.A.; Morrow, R.; Hogan, J.A.; Cavazzoni, J.; Rodriguez, L.F.; Riaño, R.; and Whitaker, D.R. (2004) An On-line Project Information System (OPIS) for Advanced Life Support. Presented at Habitation 2004 Conference, Orlando, FL

5. Levri, J.A.; Boulanger, R.; Hogan, J.A. and Rodriguez, L. (2003) "An On-line Technology 
Information System (OTIS) for Advanced Life Support" $33^{\text {rd }}$ International Conference on Environmental Systems, SAE Technical Paper 2003-01-2636. (Both paper and presentation are available at the above URL.)

6. Levri, J.A. and Hogan, J.A. (2002) "Solid Waste Management Technology Information Form". (Draft form developed by ALS Solid Waste Management Working Group.)

7. Levri, J.A.; Hogan, J.A.; Alazraki, M.P. (2002a) "Solid Waste Management Criteria Sheets" ALS Systems Integration, Modeling and Analysis teleconference presentation dated $8 / 8 / 02$.

8. Levri, J.A.; Hogan, J.A.; Alazraki, M.P. (2002b) "Solid Waste Management Criteria Sheets" ALS Technical Interchange Meeting teleconference presentation dated $6 / 6 / 02$.

9. Levri, J.A.; Hogan, J.A.; Alazraki, M.P. (2001) Evaluation Criteria for Solid Waste Processing Research and Technology Development. $17^{\text {th }}$ Annual American Society for Gravitational and Space Biology Meeting, November 7-11, Alexandria, Virginia.

10. Lange, K.E. and Lin, C.H. 1998. Advanced Life Support Program Requirement Definition and Design Considerations. Doc. no. CTSD-ADV-245 (Rev A)

11. Stafford, K.W.; Jerng, L.T.; Drysdale, A.E.; Maxwell, S.; Levri, J.A. (2001) "Advanced Life Support Systems Integration, Modeling, and Analysis Reference Missions Document," edited by Ewert, M.K. and Hanford. A.J., JSC-39502, Revision A, NASA Johnson Space Center, Houston, Texas.

\section{DEFINITIONS, ACRONYMS, ABBREVIATIONS}

AHST: Advanced Human Support Technology

ALS: Advanced Life Support

ALSSAT: Advanced Life Support Systems Analysis Tool

ARC: Ames Research Center

BP: Biomass Production

BVAD: Baseline Values and Assumptions Document

CFESH: Center for Food and Environmental Systems for Human Exploration of Space

EPSCoR: Experimental Program to Stimulate Competitive Research

ES CSTC: Environmental Systems Commercial Space Technology Center
ESM: Equivalent System Mass (see ESM Document for more detail)

FAQ: Frequently Asked Questions

FTCSC: Food Technology Commercial Space Center

GPI: General Project Information

GSRP: Graduate Student Research Program

HTML: Hyper Text Mark-up Language

HTTP: Hyper Text Transfer Protocol

MySQL ${ }^{\otimes}:$ An open-domain relational database software package (used for OPIS)

NASA: National Aeronautics and Space Administration

NRA: NASA Research Announcement

NSCORT: NASA Specialized Center of Research and Training

NTI: NASA Technology Inventory

OBPR: Office of Biological and Physical Research

OPIS: On-Line Project Information System

PHP $^{T M}$ : PHP Hypertext Preprocessor

PI: Principal Investigator

SBIR: Small Business Innovative Research

SIMA: Systems Integration, Modeling, and Analysis

TDP: Technology Development Proposal

TIA: Technology Integration Agent

TIF: Technology Information Form

TIM: Technical Interchange Meeting

TRL: Technology Readiness Level

TTA: Technical Task Agreement

TTM: Technical Task Monitor

XML: Extensible Mark-Up Language

CONTACT

John A. Hogan, Ph.D.

Education Associates Program NASA Ames Research Center

Mail Stop 239-15 
Moffett Field, CA 94035

Voice: 650-604-0152 Fax:650-604-1092 jhogan@mail.arc.nasa.gov 